\title{
Electrokinetic Analysis of the Fetal Erythrocyte Membrane After Trypsin Digestion
}

\author{
GY. KOSZTOLÁNYI AND K. JOBST
}

Department of Paediatrics, and Department of Clinical Chemistry, University Medical School, Pécs, Hungary

\begin{abstract}
Summary
Treatment of intact erythrocytes with trypsin (TRY) produced a significant difference $(P<0.001)$ in electrophoretic mobility (EM) of fetal and adult cells. The greater net negative charge of the fetal red blood cells (RBC) at the "new electrokinetic surface" generated by TRY was further analyzed with cell-electrophoretic measurements combined with various enzymatic and chemical reactions.

Formaldehyde or diazonium reaction known to eliminate positive $\left(\mathrm{NH}_{2}\right)$ groups increased the net negativity of the TRY-digested adult and fetal RBC in the same extent leaving the distance between the EM values unchanged. When the TRY digestion was followed by neuraminidase (NASE) treatment, the decrease in EM of both types of erythrocytes was of the same magnitude, and the distance between the EM values of the TRY-treated fetal and adult RBC remained unchanged, too. Phospholipase-C (PLC) digestion performed after TRY treatment did not cause any change in EM, either in adult or in fetal RBC.

The results show that the greater net negativity of the fetal RBC surface after TRY digestion can be attributed to neither less positive $\left(\mathrm{NH}_{2}\right)$ groups, nor more sialic acid or phosphoric acid molecules existing at the new electrokinetic surface. It is suggested that the fetal RBC membrane may possess more acidic amino acid exposed to the outside, when TRY liberates sialoglycoprotein from the outer surface of the membrane.
\end{abstract}

\section{Speculation}

Glycophorin seems to be the only major membrane protein in RBC which is readily accessible for TRY at the exterior cell surface. The new electrokinetic surface generated by TRY is characterized by the portion of glycophorin just behind the TRY splitting site. The results presented here might be explained by a supposed modification in the biogenesis of the glycophorin in fetal life. Amino acid analysis of the glycophorin fragments obtained with TRY digestion would serve a more intimate insight to the problem and would give information about the maturation from fetal to adult surface properties.

Human RBC are covered with glycoproteins $(6,15)$. The chemical composition and surface orientation of the major glycoprotein found in the RBC membrane (glycophorin) have been closely studied in the recent years by Marchesi and his collaborators ( 8 , 16). Its sugar-containing portion is entirely exposed to the outside of the cell and carries a number of different biological activities. It also bears the sialic acid residues responsible for the most of the negative charge at the cell surface. Because the EM of erythrocytes is mainly related to the peripheral sialic acid molecules of the membrane (12), glycophorin can be perceived as the main determinant of the erythrocyte EM.

The EM of RBC is determined by the number and sign of the ionizing groups located in the outermost region of the membrane only (12). Charged groups existing deeper in the membrane have no influence on the EM, unless they become unmasked by removing an exterior layer of the membrane, e.g., with proteolytic enzymes. TRY digestion studies on intact RBC suggest that glycophorin is the only major membrane protein which is readily accessible at the exterior cell surface (1). Accordingly, electrophoretic measurements of $\mathrm{RBC}$ combined with proteolytic digestions and other enzymatic or chemical reactions on intact RBC would give further informations about the molecular architecture of the $\mathrm{RBC}$ periphery, when the results are interpreted with respect to the chemical structure and surface orientation of glycophorin.

Fetal RBC have been shown to differ from those of adult not only in a number of metabolic characteristics (9), but in properties like membrane deformability (2) and lateral movement of membrane Concanavalin A receptors as well (11), which suggest a possible difference in membrane composition and/or structure of fetal and adult RBC. Recent studies on sodium dodecyl sulphate/ polyacrylamide gel pattern of membrane proteins failed to reveal any difference between the two-cell population (13). Previously, however, the authors reported on a dissimilarity between fetal and adult RBC in the effect of TRY digestion on the EM of intact cells (5). The work was done and the results were interpreted before the amino acid sequence and sugar attachment sites of glycophorin were appreciated (16). In experiments presented here, the difference between fetal and adult RBC membrane after TRY digestion was further analyzed with electrophoretic measurements combined with various enzymatic and chemical reactions, and the results are interpreted in the light of the knowledge about the glycophorin chemical structure.

\section{MATERIALS AND METHODS}

Venous blood from the cubital vein of 18 healthy adult volunteers and cord blood from 18 normal term infants were collected into siliconized test tubes containing sodium citrate (9:1). Each blood sample drawn from an adult was paired with that of an infant and experiments were done comparatively, treating both samples of a pair together. RBC were washed three times in "solution $S "(0.145 \mathrm{M} \mathrm{NaCl}$ adjusted to $\mathrm{pH} 7.2$ with sodium bicarbonate).

\section{FORMALDEHYDE TREATMENT}

Two $\%$ of formaldehyde was prepared from paraformaldehyde (Merck, Darmstadt, West-Germany) by the method of Vassar et al. (17). Washed RBC were suspended in this fixative and were incubated at room temperature for at least $24 \mathrm{hr}$ stirring them frequently.

\section{NASE TREATMENT}

The washed cells were suspended in $0.05 \mathrm{M}$ acetate buffer $(\mathrm{pH}$ 5.5) containing $0.9 \% \mathrm{NaCl}$ and $0.1 \% \mathrm{CaCl}_{2}$. Five $\mathrm{ml}$ of this suspension $\left(10^{\%}\right.$ cells $\left./ \mathrm{ml}\right)$ was incubated with $0.5 \mathrm{ml}$ NASE (Neuraminidase, Behringwerke AG, Marburg Lahn, West-Germany, $500 \mathrm{U} / \mathrm{ml}$ ) at $37^{\circ} \mathrm{C}$ for $30 \mathrm{~min}$. 


\section{TRY TREATMENT}

The washed $\mathrm{RBC}$ were suspended in phosphate buffered saline (PBS), $\mathrm{pH}$ 7.3. The suspension $\left(10^{7} \mathrm{cell} / \mathrm{ml}\right)$ was incubated with $1 \mathrm{mg} / \mathrm{ml}$ TRY (Trypsin 1:250, DIFCO, Detroit, MI) at $37^{\circ} \mathrm{C}$ for $60 \mathrm{~min}$.

\section{DIAZONIUM REACTION}

This procedure for deamination known in the histochemistry (10) was used for elimination of $\mathrm{NH}_{2}$ groups. Washed TRYtreated RBC were suspended in a mixture of equal parts of $10 \%$ acetic acid and $5 \% \mathrm{NaNO}_{2}$ and were incubated for $24 \mathrm{hr}$ at $4^{\circ} \mathrm{C}$.

\section{PLC TREATMENT}

Because PLC was found to be hemolytic, formaldehyde-fixed $\mathrm{RBC}$ were used for these investigations. PLC digestion was performed with a partially purified preparation (Phospholipase-C form $\mathrm{Cl}$. perfringens, Koch-Light, Colnbrook, England, 1-2 U/ $\mathrm{mg}$ ) which was protease-freed according to the procedure of Simpkins et al. (14). This enzyme preparation possessed no proteolytic activity as determined by Azocoll (Calbiochem, San Diego, CA). To avoid further unspecific effect of PLC arising from a possible contamination with neuraminidase, the fixed $R B C$ were treated with NASE before the TRY + PLC digestions. TRYtreated $\mathrm{RBC}$ were washed three times in $\mathrm{PBS}$, suspension was made $\left(10^{7}\right.$ cells $\left./ \mathrm{ml}\right)$ in solution $\mathrm{S}$ containing $\mathrm{CaCl}_{2}(0.05 \%)$, and the cells were incubated with $0.5 \mathrm{mg} / \mathrm{ml}$ protease-freed PLC at $37^{\circ} \mathrm{C}$ for $60 \mathrm{~min}$. During this incubation, the enzyme exerted its activity as was determined by the phosphorus content of the supernatant.

In successive treatments, the cells were washed three times in PBS before every next procedure. The final treatment was followed by washing the cells in solution $\mathrm{S}$, and the EM of RBC was determined in this solution at $25^{\circ} \mathrm{C}$ with an Opton Cytopherometer (Opton, Oberkochen, West-Germany) at a current intensity of $4 \mathrm{~mA}$. The migration rate of 20 cells in each sample was measured in both directions by reversing the current. The mean $\mathrm{EM} \pm \mathrm{SE}$ were expressed in term of $\mu \mathrm{sec}^{-1}$ volt $^{-1} \mathrm{~cm}$. The difference between the two types of cells were evaluated by the paired $t$ test.

\section{RESULTS}

The results are summarized in Table 1. The mean EM of untreated fetal RBC was identical with that of the adult cells. There was no significant difference in EM of the two cell types after treatment with formaldehyde and NASE. TRY digestion, however, produced a significant difference in EM of fetal and adult $\mathrm{RBC}$.

The greater net negative charge of the fetal erythrocyte surface obtained after TRY cleavage was further analyzed. Treatment of the TRY-digested cells with formaldehyde known to eliminate $\mathrm{NH}_{2}$ groups from the surface $(12,17)$ increased the net negativity of the adult and fetal RBC in the same extent leaving the distance between the EM values unchanged. Similar results were found when diazonium reaction was performed for deamination.
When the TRY digestion was followed by NASE treatment, the decrease in EM of both types of erythrocytes was of the same magnitude, and the distance between the EM values of the TRYtreated fetal and adult $\mathrm{RBC}$ remained unchanged, too.

PLC digestion of formaldehyde-fixed, desialized, and TRYtreated RBC did not cause significant change in EM, either in adult or in fetal RBC.

\section{DISCUSSION}

In experiments reported here, the EM of intact fetal and adult $\mathrm{RBC}$ was found to be the same confirming earlier results of the authors (5) and those of Luner and Szklarek (7) published independently at about the same time. Although Hollán and Szelényl (3) reported on a slight increase in EM of RBC from cord blood over the adult value, they used a different buffer system which might be a reason for this discrepancy. The authors did not find any significant difference either in the EM of the two types of cells after NASE treatment. The results imply, in agreement with those of Luner and Szklarek (7) that the actual charge density and the sialic acid moiety at the fetal and adult RBC surface are essentially identical. The lack of any effect of formaldehyde fixation on EM of fetal erythrocytes shows that, the adult RBC alike, intact fetal $\mathrm{RBC}$ do not possess detectable amount of $\mathrm{NH}_{2}$ groups at their surface. These results indicate a close similarity in molecular composition at the outer surface of fetal and adult erythrocyte membrane.

TRY treatment produced a significant difference in EM of fetal and adult RBC. TRY liberates sialoglycoproteins from the outer surface of the membrane unmasking charged groups originally existing too far from the surface (12). The charge density change occurring after TRY action, therefore, is complex, because, in addition to the elimination of protein-bound sialic acid molecules, TRY generates new charged groups which will contribute to the EM of these cells. TRY digestion, thus, results in a new electrokinetic surface of RBC.

The difference between the two types of RBC in the net charge density change caused by TRY can be attributed to either less positive or more negative groups at the new electrokinetic surface of fetal RBC. The first possibility does not appear likely, because the increase in EM of the two types of $\mathrm{RBC}$ after formaldehyde and $\mathrm{NaNO}_{2}$ treatment was of the same magnitude. Accordingly, the TRY-digested fetal RBC must have more acidic groups at their surface than those of the adult. The difference in EM of the TRY-treated fetal and adult RBC did not disappear, either, when NASE digestion was performed as a second treatment, indicating that the negative groups more in number at the new electrokinetic surface of fetal RBC may not be sialic acid, either in protein- or lipid-bound form.

PLC caused no change in EM of the fixed, desialized, TRYtreated RBC, either of fetal or of adult cells. Although data are known that the polar heads of the phospholipids of RBC membrane might be exposed to the outside (18), it seems possible that they play little, if any, role in determining the erythrocyte EM, not even after TRY removes an exterior layer from the membrane.

EM measurements serve net quantitative data only about the

Table 1. Mean EM $\pm S E$ of adult and fetal $R B C$ after various enzymatic and chemical reactions

\begin{tabular}{lcccc}
\hline \multicolumn{1}{c}{ Treatment } & $\begin{array}{c}\text { No. of experi- } \\
\text { ments }\end{array}$ & EM of adult RBC & EM of fetal RBC & $P$ \\
\hline No & 18 & $1.075 \pm 0.014$ & $1.075 \pm 0.015$ & NS \\
Formaldehyde & 5 & $1.082 \pm 0.020$ & $1.080 \pm 0.013$ & NS \\
NASE & 13 & $0.325 \pm 0.012$ & $0.297 \pm 0.014$ & NS \\
TRY & 15 & $0.678 \pm 0.014$ & $0.803 \pm 0.024$ & $<0.001$ \\
TRY + formaldehyde & 5 & $0.896 \pm 0.032$ & $1.024 \pm 0.029$ & $<0.01$ \\
TRY + NaNO & & $0.954 \pm 0.046$ & $1.074 \pm 0.030$ & $<0.05$ \\
TRY + NASE & 5 & $0.552 \pm 0.026$ & $0.675 \pm 0.028$ & $<0.02$ \\
Formaldehyde + NASE + TRY & 3 & $0.590 \pm 0.010$ & $0.690 \pm 0.017$ & \\
Formaldehyde + NASE + TRY + PLC & 3 & $0.593 \pm 0.035$ & $0.703 \pm 0.043$ & \\
\hline
\end{tabular}




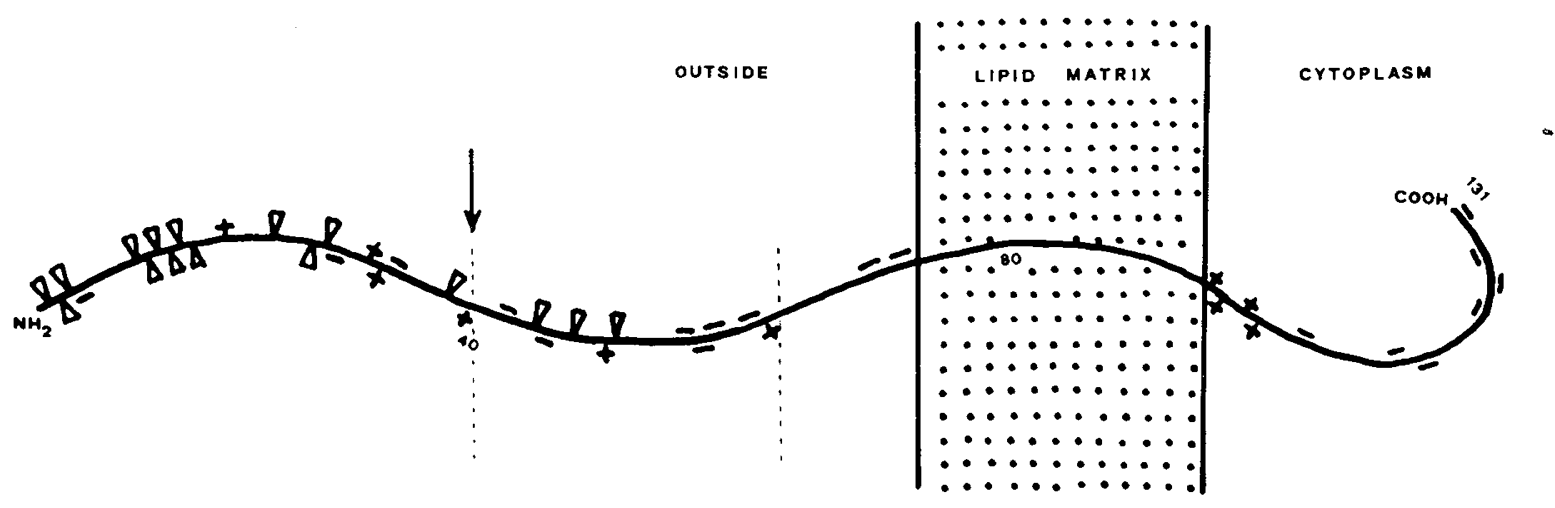

A

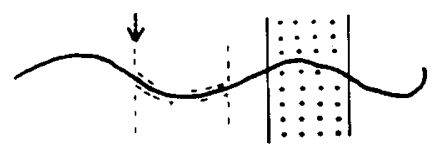

B

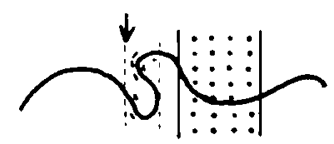

C

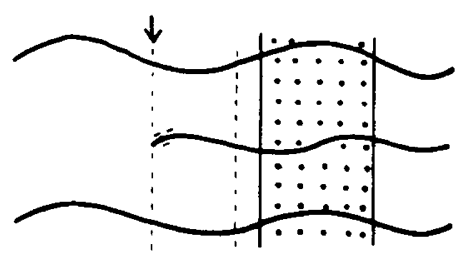

Fig. 1. Schematic representation of the surface orientation of human erythrocyte glycophorin, a single polypeptide chain of 131 amino acids to which are attached 16 oligosaccharide units (figure is based on that of Marchesi and his colleagues $(8,16)$. Triangles demonstrate the attachment sites of sugar units carrying the sialic acid molecules. The location of acidic and basic amino acid residues in the polypeptid chain are shown by ( -$)$ and $(+)$, respectively. The arrow marks the arginin linkage (at position 39) accessible to trypsin digestion when glycophorin is in situ. Dashed lines indicate the portion of glycophorin that might be different in fetal RBC. Three possibilities (A, B, C) for a tentative interpretation of our results are presented highly schematically at the bottom of the figure (see text).

cell surface potential (12). The authors have no direct evidence from this study about the chemical nature of the acidic groups responsible for the higher charge density at the new electrokinetic surface of fetal RBC. It can be said only that they might be neither of sialic acid nor phosphoric acid in origin. Nevertheless, these negative statements are important indirect informations, since they strongly suggest the third possibility, namely, that these negative groups result from the acidic amino acids of the membrane proteins.

Glycophorin seems to be the only major membrane protein in $\mathrm{RBC}$ that is readily accessible for TRY at the exterior cell surface (1). Taking into account this suggestion, the authors propose a tentative interpretation of these results with respect to the knowledge about the chemical structure of glycophorin (Fig. 1). Glycophorin molecules as single polypeptide chains with a molecular weight of 31.000 (16) are most likely fully extended due to the repulsion between negative charge of the sialic acid molecules. The EM of RBC is determined by the ionizing groups located at the outermost membrane region only, i.e., at the electrokinetic surface of the cell (12). Most of the sialic acid molecules are linked at positions too far from the electrokinetic surface and will make no significant contribution to the EM of RBC. However, they are available for NASE digestion. This may be the reason of the well known phenomenon that the yield of sialic acid released by NASE is up to about two times that expected on theoretical grounds from the change in electrophoretic charge density (12). Luner and Szklarek (7) have shown that adult and umbilical cord erythrocyte ghost are identical in their sialic acid content. These results suggest that the fetal and adult erythrocyte are identical not only in the total sialic acid content but also in the distribution of sialic acid moiety at the N-terminal end of glycophorin molecules contributing to the electrokinetic behaviour of RBC.

When intact RBC are treated with TRY, only a fragment of glycophorin is released (8) (split indicated in Fig. 1 by arrow). The new electrokinetic surface is characterized by the portion of glycophorin just behind the TRY splitting site. The suggestion that the fetal $\mathrm{RBC}$, in comparison with the adult cells, possess more acidic amino acids at the new electrokinetic surface might be explained by a supposed modification in the biogenesis of the fetal membrane proteins, namely, (A) more glutamic acid and/or aspartic acid residues exist in the polypeptide chain of "fetal glycophorin" just behind the TRY splitting site; (B) glycophorin molecules have a slightly different conformation in the fetal RBC membrane exposing more gamma carboxyl groups of glutamin acid residues to the new electrokinetic surface than in the membrane of adult RBC (glutamin acid molecules behind the TRY splitting site exist at positions $42,45,55,56,57,60) ;(C)$ in addition to the fully-matured polypeptide chain, the fetal RBC membrane might also have preformed, incomplete glycophorin molecules extending only up to the membrane level at the TRY splitting site.

Data are known that the major proteins of the RBC membrane appear gradually in the newly formed erythrocyte during erythropoesis (4). Comparative studies on the surface architecture of fetal and adult RBC like these would give information about the maturation from fetal to adult surface properties as well.

\section{REFERENCES AND NOTES}

1. Carraway, K. L., Kobylka, D., and Triplett, R. B.: Surface proteins of erythrocyte membranes. Biochim. Biophys. Acta, 241: 934 (1971).

2. Gross, G. P., and Hathaway, W. E.: Fetal erythrocyte deformability. Pediatr. Res., 6: 593 (I972).

3. Hollán, S. R., and Szelényi, J. G.: Structural and functional differences between human foetal and adult erythrocytes. Haematologia, 4: 409 (1967).

4. Kadlubowsky, M., and Harris, J. R.: The appearance of a protein in the human erythrocyte membrane during ageing. FEBS Lett, 47: 252 (1974).

5. Kosztolányi, Gy., and Jobst, K.: Electrophoretic mobility of the fetal red blood cell. Biol. Neonate, 27: 125 (1975).

6. Luft, J. H.: The structure and properties of the cell surface coat. Int. Rev. Cytology, 45: 291 (1976).

7. Luner, S. J., and Szklarek, D.: Comparison of electrophoretic mobility and membrane sialic acid content of erythrocytes from adult and umbilical cord blood. Pediatr. Res., 9: 583 (1975).

8. Marchesi, V. T., Tillack, T. W., Jackson, R. L., Segrest, J. P., and Scott, R. E.: Chemical characterization and surface orientation of the major glycoprotein of 
the human erythrocyte membrane. Proc. Nat. Acad. Sci. USA, 69: 1445 (1972).

9. Oski, F. A., and Komazawa, M.: Metabolism of the erythrocytes of the newborn infant. Semin. Hematol. 12: 209 (1975).

10. Pearse, A. G. E.: Histochemistry, p. 800 (Churchill, London, 1960).

11. Schekman, R., and Singer, S. J.: Clustering and endocytosis of membrane receptors can be induced in mature erythrocytes of neonatal but not adult humans. Proc. Nat. Acad. Sci. USA, 73: 4075 (1976).

12. Seaman, G. V. F.: Electrokinetic behaviour of red cells. In: D. M. Surgeon: The Red Blood Cell. p. 1135 (Academic Press, New York, 1975).

13. Shapiro, D. L., and Pasqualini, P.: Erythrocyte membrane proteins of premature and full-term newborn infants. Pediatr. Res., 12: 176 (1978).

14. Simpkins, H., Panko, E., and Tay, S.: Evidence which suggests the existence of lipid regions discrete from those of the proteins in mitochondrial and red blood cell membranes. J. Membr. Biol., 5: 334 (1971).

15. Steck, T. L.: The organization of proteins in the human red blood cell membrane. J. Cell Biol., 62: 1 (1974)

16. Tomita, M., and Marchesi, V. T.: Amino-acid sequence and oligosaccharide attachment sites of human erythrocyte glycophorin. Proc. Nat. Acad. Sci. USA, 72: 2964 (1975).

17. Vassar, P. S., Hards, J. M., Brooks, D. E., Hagenberger, B., and Seaman, G. V. F.: Physicochemical effect of aldehydes on the human erythrocyte. J. Cell Biol, 53: 809 (1972)

18. Zwaal, R. F. A., Roelofsen, B., and Colley, C. M.: Localization of red cell membrane constituents. Biochim. Biophys. Acta, 300: 159 (1973).

19. Received for publication November 15,1978 .

20. Accepted for publication February 12, 1979. 